\title{
Numerical investigation of shallow water resistance of a planing vessel
}

\author{
[Amir H. Nikseresht, Ali Safari]
}

\begin{abstract}
In recent years a great deal of research effort on ship hydrodynamics have been devoted to practical navigation problems in moving planing vessels safety in rivers and confined water. The important point of any analysis is the investigation of ship hydrodynamics in shallow water conditions. The purpose of this study is to investigate the resistance of a planing vessel model 4667-1 by using CFD software based on finite volume method to solve the RANS equations in different speed and depths including deep and shallow water conditions. Also the wave pattern and flow field around the vessel is investigated. For validating the method, at first the resistance results in deep water are compared with the experimental data and show good agreements. Simulations are performed in transient mode, using Volume of Fluid (VOF) and $k-\varepsilon$ schemes to model the free surface turbulent flow. The results have shown that by decreasing the depth, the shallow water resistance of a planing vessel will be increased.
\end{abstract}

Keywords - Shallow water, Deep water, Resistance, planing vessels, Volume of Fluid

\section{Introduction}

To determine the power requirements of marine crafts, first the resistance of a craft must be obtained. The resistance can be investigated by various methods such as numerical, analytical, empirical or experimental. The experimental and numerical methods are the most popular ones. Usually in the experimental methods according to the facilities or the size of the laboratory, the scaled models are used to simulate and the results of the prototype are determined using dimensionless analyses. With lack of resources to satisfy all similarity conditions some errors can occur in the experimental results which are sometimes called as the scale effects. Although the accuracy of experimental results is good, but due to the high need for resources such as cost and time in experimental methods, some researchers prefer to use numerical methods.

Amir H. Nikseresht, Associate Prof. of Mechanical Engineering Mechanical and Aerospace Engineering Department, Shiraz University of Technology

Shiraz, Iran

Ali Safari, Master of Science of Mechanical Engineering

Mechanical and Aerospace Engineering Department, Shiraz University of Technology.

Shiraz, Iran
According to the depth of the water shipping routes are divided into shallow water and deep water, in each of which marine vessels require different powers for driving. Due to the hydrodynamic effects of shallow water, planing vessels show different behavior in shallow water in comparison with deep water. There is a particular research interest in calculation of ship resistance in shallow water or restricted water in different speeds. As the vessel moves in shallow water the interaction of vessel and sea bed appears and causes the increase of flow speed and pressure reduction between the hull bottom and the sea bed. The consequent reduction in pressure around the hull leads to reduction in buoyant force and increase in the draft of the vessel. The increase in the draft leads to increase in the friction resistance and also may change the trim angle. The wave pattern in shallow water will be changed and so the wave making drag increases as well.

Theoretical methods were first used by Von Karman [1] for solving 2D problems in 1929 and also these methods were extended to the 3D steady planing surfaces [2]. Potential flow theory have been used to determine the behavior of planing hulls in calm water and also the seakeeping in wave $[3,4]$.

In the first crafts numerical resistance studies, the inviscid flow theorem was used. With this assumption only the pressure resistance can be calculated $[5,6]$. In later researches the effects of viscosity and free surface nonlinearity were found to be necessary for calculating the frictional resistance and wave making drag [7, 8]. Calculating of hydrodynamic impact loads is also one of the critical design issues for planing crafts. Typically, empirical methods have been used for evaluating hydrodynamic forces and stability behavior of planing vessels $[9,10]$. RANS simulations are carried out to predict the forces and moments acting on a simple constant dead-rise prismatic planing surface [11], and recently it is also extended to simulate the stepped hulls with partially ventilated bottom [12]. T. O'Shea et al., show the grid design and topology are very important to obtain a reasonable agreement between the numerical and experimental results in the study of a prismatic geometry ship with free to trim condition using the Euler code in a calm deep water [13].

The purpose of this study is to investigate the resistance of a planing vessel model $4667-1$ by using CFD software to solve the RANS equations in different speed and depths including deep and shallow water conditions and also to study the wave pattern and flow field around the vessel. For validating the method, the numerical resistance results in deep water are compared with the experimental data of [14]. 
Proc. of The Third Intl. Conf. On Advances in Civil, Structural and Mechanical Engineering - ACSM 2015

Copyright (C) Institute of Research Engineers and Doctors, USA .All rights reserved.

ISBN: 978-1-63248-083-5 doi: 10.15224/ 978-1-63248-083-5-62

\begin{tabular}{|ccc|}
\hline Nomenclature & & \\
$d$ & Water depth & $A_{P}$ \\
$F_{T}$ & Total resistance & $B_{L}$ \\
$F_{R}$ & Added resistance in shallow water & $L_{P}$ \\
$\mathrm{~V}$ & Speed & $L_{C G}$ \\
$\mathrm{~S}$ & Wetted surface area & $C_{L}$ \\
$F_{\nabla}$ & Froude number & $L_{K}$ \\
$C_{d}$ & Non-dimensional total resistance & $C_{r}$ \\
\hline
\end{tabular}

\section{Governing equations}

Since the flow is considered as incompressible Turbulent flow, continuity and momentum equations are as follows:

$\vec{\nabla} \cdot \vec{V}=0.0$

$\frac{\partial \vec{V}}{\partial t}+(\vec{\nabla} \cdot \vec{V}) \vec{V}=\frac{1}{\rho} \vec{\nabla} \cdot \sigma+\vec{g}$

where $\sigma$ is stress tensor and is equal to:

$\sigma_{i j}=-p S_{i j}+2\left(\mu+\mu_{t}\right) S_{i j}$

where $p, S, \mu, V, \rho$ and $\vartheta$ are static pressure, strain tensor rate, dynamic viscosity, fluid velocity, fluid density and kinematic viscosity, respectively. Note that the dynamic condition, i.e., continuity of pressure at the interface is automatically implemented. The kinematic condition, which states that the interface is convected with the fluid, can be expressed in terms of volume fraction $\varphi$ as follows:

$\frac{D \varphi}{D t}=\partial_{t} \varphi+\vec{V} \cdot \vec{\nabla} \varphi=0.0$

In the VOF method, the interface is described implicitly, the data structure that represents the interface is the fraction $\varphi$ of each cell that is filled with a reference phase, say phase 1 . The scalar field $\varphi$ is often referred to as the color function. The magnitude of $\varphi$ in the cells cut by the free surface is between 0 and $1(0<\varphi<1)$ and away from it is either zero or one. $\mu$ and $\rho$ at any cell (denoted by $i j$ ) can be computed using $\varphi$ by taking a simple volume average over the cell

$\rho_{i j}=\varphi_{i j} \rho_{L}+\left(1-\varphi_{i j}\right) \rho_{a}$

$\mu_{i j}=\varphi_{i j} \mu_{L}+\left(1-\varphi_{i j}\right) \mu_{a}$

where subscripts (L) and (a) denote liquid and air respectively.

\section{Numerical schemes}

The most common method of generating the vessel's geometry is the use of stations along the vessel, which is called the body plan. The number of stations is typically 10 to 20. The distance between stations is equal, except in the bow and stern which have drastic changes. In this research, 10 longitudinal stations are used for generating the planing craft geometry. The last station which is located in the vessel stern, is the basis of static draft calculation. The specifications of the planing vessel model $4667-1$ which is analyzed in this article and test condition are shown in Table I. Also the 3D shape of the planing vessel model 4667-1 is shown in Fig. 1.

$$
\begin{aligned}
& \text { Projected planning bottom area, excluding the area of } \\
& \text { external spray stripes } \\
& \text { Baseline } \\
& \text { Projected chine length }
\end{aligned}
$$

Longitudinal center of gravity location

Centerline

Projected keel length

Non-dimensional added resistance

A Cartesian coordinate system $(\mathrm{x}, \mathrm{y}, \mathrm{z})$ fixed at the stern of the vessel is used. The coordinate system is oriented such that the $z$-axis points upward and the negative direction of $x$-axis points in the forward direction of the planing vessel. To investigate the effect of shallow water on the resistance of a planing vessel, simulations were performed in 3 different depths of $2.5,0.3$ and $0.1 \mathrm{~m}$. The results of the 2.5 meter depth are considered as a deep water data and are compared with the experimental results of reference [14]. Simulations are performed in 4 various Froude numbers of 0.6, 1.5, 4.51 and 4.99. At Froude number 0.6, the resistance of a planing vessel is the same as a displacement vessel because the vessel speed is low and the wetted surface area is large. At Froude number 1.5, the vessel is in the semi-planing state and at Froude numbers 4.51 and 4.99 the vessel is in the planing state. The purpose of choosing these Froude numbers is investigating the effect of shallow water on the resistance of a planing craft in all possible states.

TABLE I. THE SPECIFICATIONS OF THE PLANING VESSEL MODEL 4667-1 AND TEST CONDITION [14]

\begin{tabular}{c|c|c|c}
\hline$\alpha, \mathrm{deg}$ & $\begin{array}{c}\text { Draft above BL at } \\
\text { sta. } 10, \mathrm{~m}\end{array}$ & $\begin{array}{c}\text { LCG Fwd of sta. } \\
10, \mathrm{~m}\end{array}$ & $\mathrm{~L}_{\mathrm{P}}, \mathrm{m}$ \\
\hline 2.4384 & 1.105 & 0.113284 & -0.32 \\
\hline
\end{tabular}

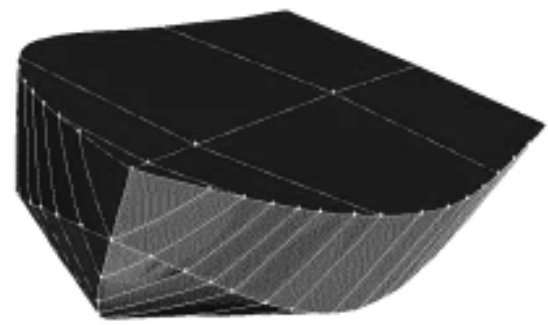

Figure 1. 3D shape of the planing vessel model 4667-1

Due to symmetry of the geometry and boundary conditions about the $\mathrm{X}$-axis passing through the body, only half of the vessel is meshed and simulated. The velocity inlet is chosen as the inlet water and air phase boundary conditions. In the outlet the fully developed flow or outflow is set. Also the velocity inlet is set for the upper, lower and side surfaces. The no slip boundary condition is defined for the planning vessel.

In this paper, the domain around the planing vessel is discretized with the hexahedral structured meshes. Near the walls of the vessel and also in the interface the meshes are finer to capture the interface and also the wake near the body 
better. This is done by using the boundary layer meshes near the walls of the vessel. In the present study, a finite volume code is used to simulate the flow field around the vessel, second order upwind numerical scheme is used to discretize the convective terms of the momentum equations and standard SIMPLE algorithm is used for coupling the pressure and velocity based equations. Also explicit VOF scheme is used to capture the interface in two phase flow and the standard k-e method is used to simulate the turbulent flow. A grid independency study was performed by comparing the results of 800 thousands, 1.6 and 2.1millions meshes. In table II., resistance coefficients have been reported for the whole vessel at Froude numbers of 0.6 and 4.51. The percent of the relative error of the resistance coefficients are presented with respect to the experimental data of [14]. Also to show the time independency, three time steps of $0.005,0.001$, and 0.0005 seconds are considered. By comparing again the numerical resistance coefficient at $\mathrm{Fr}=4.99$ with experimental results, it is seen that the percent of the relative error of the first and the second one is $11 \%$ and the percent of the relative error of the second and third models is less than $0.05 \%$. So the 0.001 second time step is used for the whole calculations. Also to show the time independency, three time steps of $0.005,0.001$, and 0.0005 seconds are considered. By comparing again the numerical resistance coefficient at $\mathrm{Fr}=4.99$ with experimental results, it is seen that the percent of the relative error of the first and the second one is $11 \%$ and the percent of the relative error of the second and third models is less than $0.05 \%$. So the 0.001 second time step is used for the whole calculations. Furthermore, by testing the domain independency, the dimensions of the domain around the vessel are obtained as follows (the term $L_{P}$ refers to the length of the vessel.):

- The inlet surface, the top surface, and the bottom surface are $3 L_{P}$ far away from the nose of the vessel

- The side surface is $3 L_{P}$ far away from the body of the vessel.
- The outlet surface is $6 L_{P}$ far away from the end of the vessel.

\section{Results}

In this study, at first the resistance of the vessel in deep water is investigated. Table III. shows the experimental change of the trim angle and CG rise which is used to fix the trim condition and draft line in numerical analysis of various Froude numbers in deep water. The dimensionless drag force or resistance of the vessel $\left(C_{d}=\frac{F_{T}}{\frac{1}{2} \rho S V^{2}}\right)$ is investigated in deep water for each Fr. No. and is compared with experimental data in Table III. The comparison of results shows a good agreement. In the following resistance of the vessel is investigated in shallow water with the same conditions as in deep water in two different depths. In each depth the difference of resistance in shallow water with respect to deep water is calculated and indicated as $F_{R}$. For better investigation the dimensionless coefficient of residual or added resistance is defined as $\quad C_{\mathrm{r}}=\frac{F_{R}}{\frac{1}{2} \rho S V^{2}}$ where $\mathrm{S}$ is the wetted area which is indicated in Table III. In Fig. 2 (a) and 2 (b), the total resistance coefficient and added resistance coefficient in different depths are depicted respectively. Reducing the depth of water, will increase the total resistance coefficient and added resistance coefficient. It is obvious that the maximum resistance occurs at Froude number of 1.5 and by further increasing the Froude number the total resistance coefficient and added resistance coefficient decrease again. As it is depicted in Fig. 3, it is obvious that with decreasing the depth in a constant Froude No. the water draft line will increase and it is the main reason for the increase in the added resistance in shallow water. As it is seen in Fig 3(b) the maximum draft has also occurred at Froude No. 1.5, but the maximum difference between the drafts in the two shallow water depths has appeared at Froude No. 4.51 (Fig. 3 (c)).

TABLE II. THE COMPARISON OF RESISTANCE COEFFICIENT OF PLANING VESSEL FOR 3 COMPUTATIONAL GRIDS WITH EXPERIMENTAL RESULTS [14]

\begin{tabular}{c|c|c|c|c|c|c|c}
\hline $\begin{array}{c}\text { Froude } \\
\text { number }\end{array}$ & $\begin{array}{c}\mathrm{C}_{\mathrm{d}} \times 10^{3} \\
\text { Experiment } \\
{[14]}\end{array}$ & $\begin{array}{c}\mathrm{C}_{\mathrm{d}} \times 10^{3} \mathrm{Grid} \\
1 \text { (Coarse) }\end{array}$ & Error (\%) & $\begin{array}{c}\mathrm{C}_{\mathrm{d}} \times 10^{3} \mathrm{Grid} \\
2(\mathrm{Mid})\end{array}$ & $\begin{array}{c}\text { Error (\%) } \\
\mathrm{C}_{\mathrm{d}} \times 10^{3} \text { Grid } \\
3 \text { (Fine) }\end{array}$ & Error (\%) \\
\hline 0.6 & 11.4 & 12.6 & 10.5 & 11.84 & 3.86 & 11.82 & 3.68 \\
4.51 & 4.851 & 5.47 & 12.76 & 5.016 & 3.4 & 5.01 & 3.28 \\
\hline
\end{tabular}

TABLE III. THE COMPARISON OF RESISTANCE COEFFICIENT RESULTS OF A PLANING VESSEL IN DEEP WATER WITH EXPERIMENTAL RESULTS [14]

\begin{tabular}{|c|c|c|c|c|c|c|c|}
\hline $\begin{array}{l}\text { Froude } \\
\text { number }\end{array}$ & Velocity $(\mathrm{m} / \mathrm{s})$ & $\begin{array}{c}\text { Wetted area } \\
\qquad\left(\mathrm{m}^{2}\right)\end{array}$ & $\begin{array}{l}\text { Change of } \\
\text { trim (deg) }\end{array}$ & $\begin{array}{l}\text { CG rise } \\
(\mathrm{cm})\end{array}$ & $\begin{array}{l}\qquad \mathrm{C}_{\mathrm{d}} \times 10^{3} \\
\text { Experiment [14] }\end{array}$ & $\begin{array}{c}\mathrm{C}_{\mathrm{d}} \times 10^{3} \\
\text { numerical }\end{array}$ & Error (\%) \\
\hline 0.6 & 1.286 & 1.369 & -0.17 & -0.6096 & 11.4 & 11.84 & 3.86 \\
\hline 1.5 & 3.1896 & 1.385 & 3.34 & -0.5334 & 16.754 & 16.387 & 2.19 \\
\hline 4.51 & 9.6098 & 0.785 & 3.45 & 6.858 & 4.851 & 5.016 & 3.4 \\
\hline 4.99 & 10.66443 & 0.766 & 3.32 & 7.5438 & 4.443 & 4.34 & 2.1 \\
\hline
\end{tabular}

Also it can be seen, that with decreasing the water depth the wave height increases only in the middle of the vessel and there is no significant effect on the wave height of the bow and stern. As it is depicted in Fig. 4 and Fig. 5 in both Froude 
numbers of 0.6 and 4.99 , the vortices which are created at the back of the planing vessel are longer and more strengthen in shallow water compared with the deep water and also the flow regime is more irregular. According to Fig. 4, at Froude number 0.6 , the waves which are created in the bow of the vessel are the reason of greater resistance in this Froude number. But at Froude number 4.99, these waves are not seen. Other main reasons of reduction of resistance coefficient at

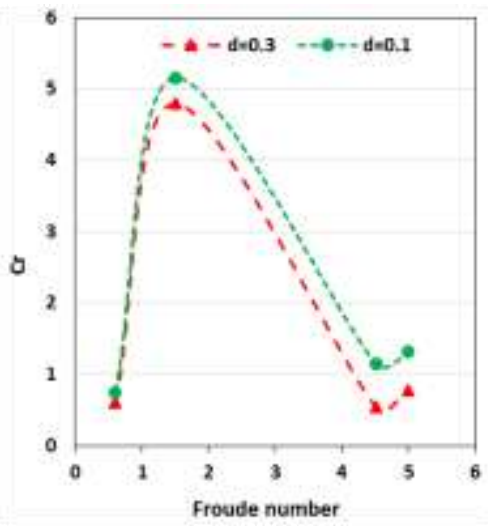

(b)
Froude number 4.99 compared with Froude number 0.6 is the creation of cross waves through the bow of the vessel. At Froude number 0.6, waves break after impacting on the bow of the vessel and spray on the bow and body of the craft, but at Froude number of 4.99 due to planing regime of the vessel the body of the craft comes up completely, therefore the flow spray from the bottom of the craft and the wetted area decreases, so the resistance also decreases.

Figure 2. Resistance coefficient of a planing vessel a) total resistance coefficient b) added resistance coefficient

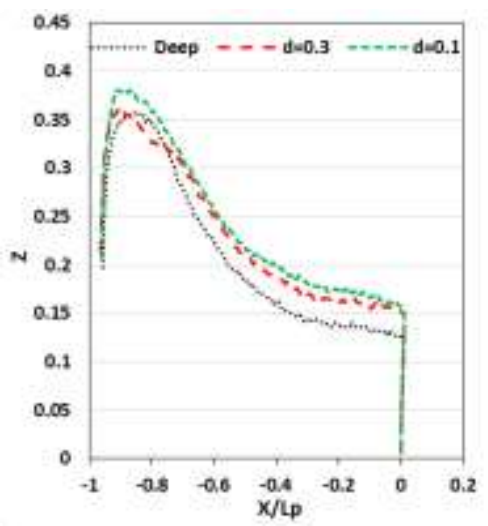

(b)

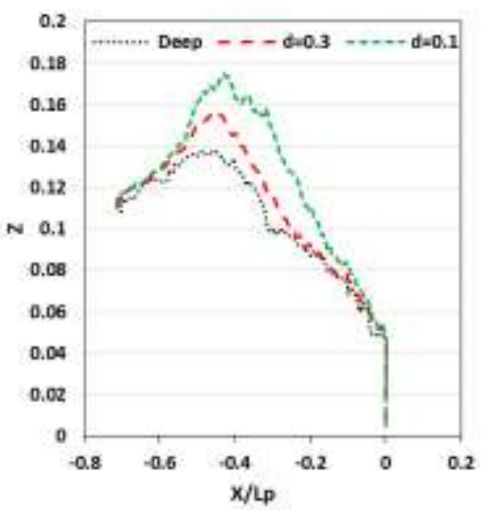

(d)

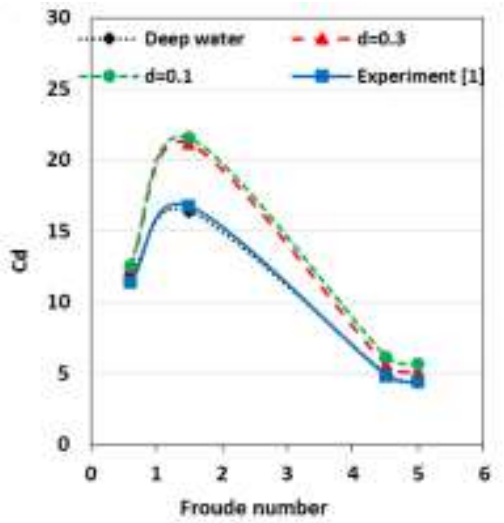

(a)

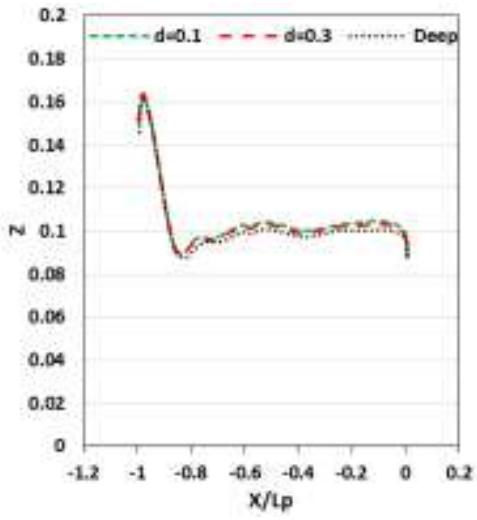

(a)

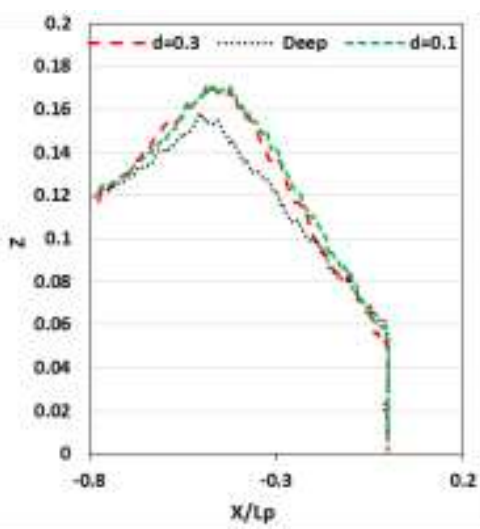

(c)

Figure 3. Wave pattern of the planing vessel in deferent depths. a) Froude number 0.6, b) Froude number 1.5, c) Froude number 4.51 d) F Froude number 4.99 
Proc. of The Third Intl. Conf. On Advances in Civil, Structural and Mechanical Engineering - ACSM 2015 Copyright $(\odot$ Institute of Research Engineers and Doctors, USA .All rights reserved. ISBN: 978-1-63248-083-5 doi: 10.15224/ 978-1-63248-083-5-62

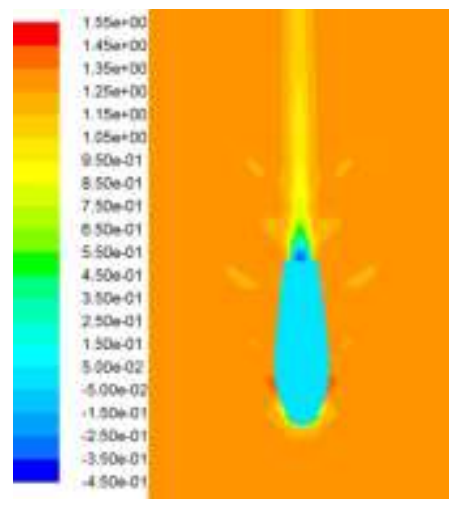

(c)

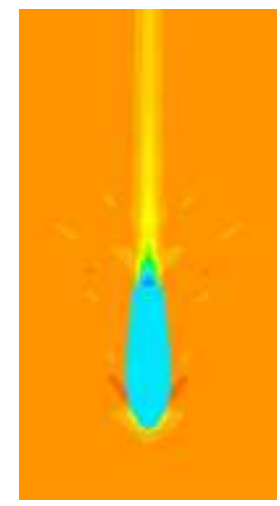

(b)

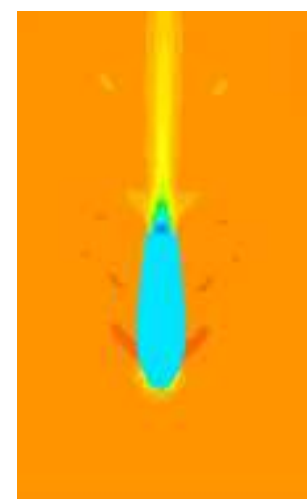

(a)

Figure 4. Flow field in computational domain at Froude number $0.6 \mathrm{a}$ ) in depth $0.1 \mathrm{~m} \mathrm{~b}$ ) in depth $0.3 \mathrm{~m}$ c) in deep water

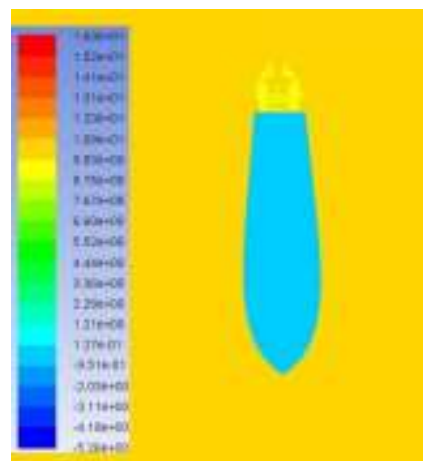

(c)

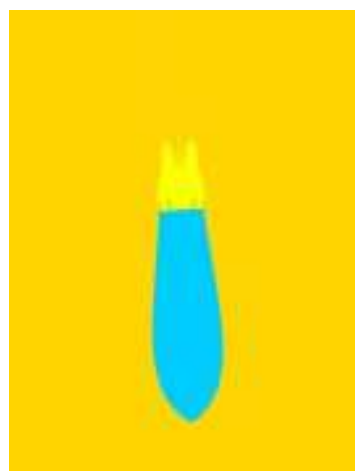

(b)

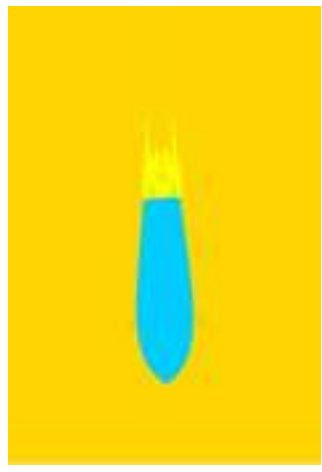

(a)

Figure 5. Flow field in computational domain at Froude number 4.99 a) in depth $0.1 \mathrm{~m} \mathrm{~b}$ ) in depth $0.3 \mathrm{~m} \mathrm{c}$ ) in deep water

\section{v. Conclusion}

In this paper, the effect of shallow water on the resistance of a planing vessel model 4667-1 in different depths and Froude numbers is investigated. The comparison between the present computations and experimental data in deep water shows the good accuracy of the present numerical simulation to predict the resistance force. The results show that the resistance force increases with decreasing the water depth and also it is shown that there is a Froude number in which the resistance and also the added resistance are maximum. Also it is deduced that by reducing the water depth the flow field after the vessel becomes more irregular and also the wetted area due to the wave pattern increases.

\section{References}

[1] T. Von Karman, "The impact on seaplane floats during landing," 1929.

[2] B. R. Savander, S. M. Scorpio, and R. K. Taylor, "Steady hydrodynamic analysis of planing surfaces," Journal of ship research, vol. 46, pp. 248$279,2002$.

[3] A. Iafrati and R. Broglia, "Comparisons between 2D+t potential flow models and 3D RANS for planing hull hydrodynamics," in Proceedings of 25th international workshop on water waves and floating bodies, Harbin, China, 2010.

[4] P. De Jong, Seakeeping behaviour of high speed ships: An Experimental and Numerical Study: TU Delft, Delft University of Technology, 2011.

[5] M. Hasanadil, "Hydrodynamic coefficients of ships with forward speed in shallow waters," 船舶力学, vol. 8, pp. 46-54, 2004.
[6] S. Rigby, D. Nicolaou, J. Sproston, and A. Millward, "Numerical modeling of the water flow around ship hulls," Journal of ship research, vol. 45, pp. 85-94, 2001.

[7] H. Orihara, "Validation of numerical method for predicting hydrodynamic characteristics of a high-speed ship," in 24th Symposium on Naval Hydrodynamics, Fukuoka, Japan, 2002.

[8] Y. Andrillon and B. Alessandrini, "A 2D+ T VOF fully coupled formulation for the calculation of breaking free-surface flow," Journal of marine science and technology, vol. 8, pp. 159-168, 2004.

[9] P. W. Brown, "An experimental and theoretical study of planing surfaces with trim flaps," DTIC Document1971.

[10] C. J. Reyling, "An experimental study of planing surfaces operating in shallow water," DTIC Document 1976.

[11] S. Brizzolara and F. Serra, "Accuracy of CFD codes in the prediction of planing surfaces hydrodynamic characteristics," in 2nd International Conference on Marine Research and Transportation, 2007, pp. 147-159.

[12] S. Brizzolara and A. Federici, "CFD modeling of planning hulls with partially ventilated bottom," in The William Froude Conference: Advances in Theoretical and Applied Hydrodynamics-Past and Future. Portsmouth, 2010, pp. 24-25.

[13] T. O'Shea, K. Brucker, D. Wyatt, D. Dommermuth, and T. Fu, "A detailed validation of numerical flow analysis (NFA) to predict the hydrodynamics of a Deep-V planing hull," in Proceedings of The Third Chesapeake Power Boat Symposium, Society of Naval Architects and Marine Engineers, 2012, pp. 15-16.

[14] E. P. Clement, Resistance tests of a systematic series of planing hull Forms: Society of Naval Architects and Marine Engineers, 1963. 